\title{
ANALYSIS OF THE NUMBER AND ANGLE OF THE IMPELLER BLADE TO THE PERFORMANCE OF CENTRIFUGAL PUMP
}

\author{
Sugeng Hadi Susilo $\bowtie$ \\ Department of Mechanical Engineering ${ }^{l}$ \\ shadis172.gh@gmail.com,sugeng.hadi@polinema.ac.id \\ Agus Setiawan \\ Department of Mechanical Engineering ${ }^{l}$ \\ ${ }^{1}$ State Polytechnic of Malang \\ $9 \mathrm{Jl}$. Soekarno-Hatta, Malang, East-Java, Indonesia, 65141
}

$\triangle$ Corresponding author

\begin{abstract}
The paper discusses the performance of the pump in relation to the impeller. The impeller section is determined by the number and angle of the blades. Therefore, the purpose of this study was to analyze the role of the number and angle of impeller blades on the performance (discharge and discharge pressure) of centrifugal pumps based on experiments and simulations.

The method used is experiment and simulation. Using a centrifugal pump type GWP 20/4 SW, Maximum Output: 6.5 HP/3500 rpm, Inlet/Outlet: 2 Inch, Dimensions: $475 \times 375 \times 370 \mathrm{~mm}$. Experiments and simulations by varying the number of blades 2,4 , and 6 with a blade tilt angle of $130^{\circ}, 150^{\circ}$, and $160^{\circ}$. For flow simulation using solid works program.

The results show that pump performance is related to discharge pressure, impeller with 2-blades and an angle of $130^{\circ}$ the pressure increases $0.45-2.45$ bar, for $150^{\circ}$ increases $0.14-2.96$ bar, and $160^{\circ}$ increases $0.29-3.07$ bars. For a 4-blade impeller and an angle of $130^{\circ}$, the pressure increases by $0.48-3.12$ bar, for $150^{\circ}$ it increases by $0.39-3.39$ bar, and for $160^{\circ}$ it increases by $0.36-3.48$ bar. While the impeller for 6-blades with an angle of $130^{\circ}$ the pressure increases from 0.6 bar to 3.72 bar, for $150^{\circ}$ increases from 1.36 to $4.34 \mathrm{bar}$, and $160^{\circ}$ increases by $0.36-4.74$ bar. While it related pump performance to flow rate, increasing the number of blades causes a decrease in flow rate. The highest flow rate is in a 2-blade impeller with a blade angle of $130^{\circ}$ is $404.911 / \mathrm{s}$. The lowest flow rate is on a 6-blade impeller with an angle of $160^{\circ}$ is $279.661 / \mathrm{s}$.
\end{abstract}

Keywords: pump performance, centrifugal pump, impeller, number of blades, blade angle, simulation, experiment.

DOI: $10.21303 / 2461-4262.2021 .002001$

\section{Introduction}

Water is a very vital need for survival, be it humans, animals or plants. Besides irrigation needs, but also for the supply of raw water, clean water, industrial water, electricity, plantations and other business activities that require water. With the increase in population, the need for water also increases. So that pumps are necessary to drain water from one place to another, and pumps are needed in human life in various fields $[1,2]$. The pump serves to move the fluid through the pipe from one place to another [3].

The function of the pump is to change the mechanical energy of the shaft that moves the blades into kinetic energy and pressure in the form of the head in the fluid. The impeller is an important component in a centrifugal pump, and the most important part is the number and angle of the blades. This affects the performance of the pump. Pump performance is determined by the output pressure, flow capacity or flow rate, and suction strength [4].

Pump design requires a trial-and-error process, reducing the pump manufacturer's profit margins. For analytical reasons, besides experiments, simulations were also carried out at the pump design and construction stages [5]. Instability and dynamic phenomena can be studied with the help of simulation. Simulation can provide fairly accurate information about fluid behaviour, thus helping in evaluating pump performance [6].

The need for pumps in human life in various fields. For agriculture, pumps are widely used in the irrigation system so that the agricultural system continues to run even in the dry season, 
in providing drinking water for the community, pumps are used to distribute drinking water from PDAM to people's homes, pumps are a tool that facilitates daily human work [7]. Therefore, research is needed that discusses the effect of the impeller exit angle $(\beta 2)$ on performance which includes discharge and exhaust pressure in centrifugal pumps. The role of the number of blades and the angle of the blade on the impeller affect the resulting pump pressure.

To optimize pump performance, a pump impeller is needed which plays an important role in determining the pump output pressure and flow capacity. The influence of the number of blades and the angle of the blades will cause the number of blades to change and affect the resulting pump pressure.

Research on the optimization of centrifugal pump impeller performance using design standards. Simulation is used to validate experimental test results. The experimental results were analyzed for the best combination of parameters and compared with the original pump. Research on the optimization of pressure and efficiency of centrifugal pumps to get high efficiency in using low power in operation. This study increases the head and efficiency of the centrifugal pump by changing the impeller blades and the exit angle of the centrifugal pump blades to get optimal head and efficiency [8].

This research on Centrifugal Pump Impeller Design Optimization research with the CFD approach discusses the stages of pump construction design. Based on the design results, to determine the optimal number of blade variations [9].

Research on the effect of the inlet impeller reverses 6 angles on the characteristics of the FM 50 centrifugal pump. This study discusses the effect of the inlet angle of the impeller $(\beta 1)$ of the pump on the centrifugal pump head for each impeller with an intake angle. The results showed that the value $(\beta 1)$ of the impeller did not affect the performance of the pump, but because the circulation in the impeller caused the performance of the pump to change. Based on the results of the study, it is known that the greater the head value $(\beta 1)$, the hydraulic power of the pump will increase. The pump flow rate also increases. On the other hand, the greater $(\beta 1)$, the smaller the pump efficiency produced [10].

Numerical simulation of backward impeller type centrifugal pump with variations in rotation and pump discharge. Numerical simulations were carried out on 2D and 3D steady flow with a standard turbulent k-epsilon model. Simulation by varying the speed and flow of the pump. Then the simulation results are validated with experimental results. The results obtained in the $2 \mathrm{D}$ numerical research are very different from the experimental results. In the $3 \mathrm{D}$ simulation, there is a backflow phenomenon [11].

Therefore, researchers conducted experiments and simulated the effect of the impeller exit angle on performance which includes discharge, discharge pressure on a centrifugal pump by using the influence of the number and exit angle of the impeller.

\section{Materials and methods}

\section{1. Centrifugal pump specifications}

The type of pump used in this study is GWP 20/4 SW. Following are the specifications for the Centrifugal Pump Type GWP 20/4 SW, Maximum Output: 6.5 HP/3500 RPM, Inlet/Outlet: 2 Inch, Dimension: $475 \times 375 \times 370 \mathrm{~mm}$. The impeller design is shown in Fig. 1 .

Fig. 1 shows the design of the blade position and blade angle for 2 variations of the blade angle of $160^{\circ}$. Manufacturing this impeller uses the welding method so that it can form a precise construction. The number of blades 2,4 , and 6 varied with blade angles of $130^{\circ}, 150^{\circ}$, and $160^{\circ}$.

\section{2. Experimental setup}

The study used a 2-inch GWP 20/4 SW centrifugal pump. The research was conducted by varying the number and angle of the blades using experimental and simulation methods. In this study, the number of blades 2,4 , and 6 varied with blade angles of $130^{\circ}, 150^{\circ}$, and $160^{\circ}$. Fig. 2 shows the experimental setup.

The experimental set-up consists of 3 main parts, namely preparing the equipment to be tested, preparing the pump, and taking data. 

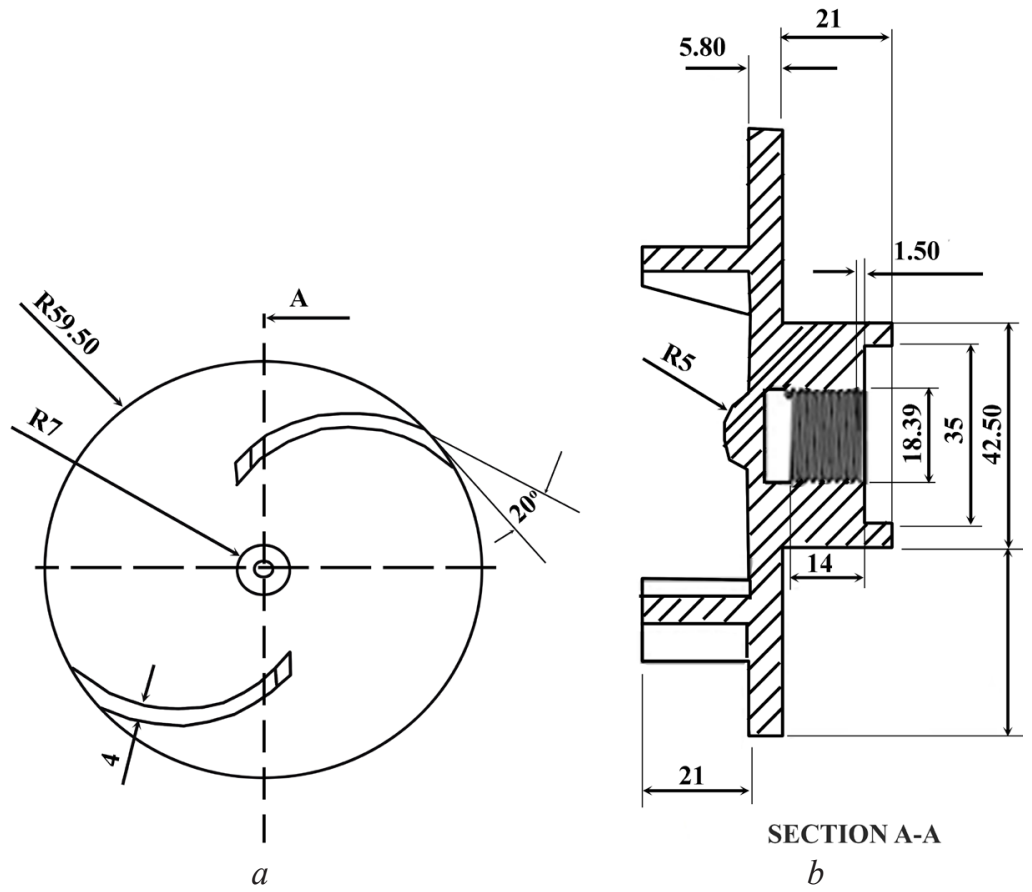

Fig. 1. Design of impeller for 2-blade $160^{\circ}: a$ - Front view; $b$ - Section A-A

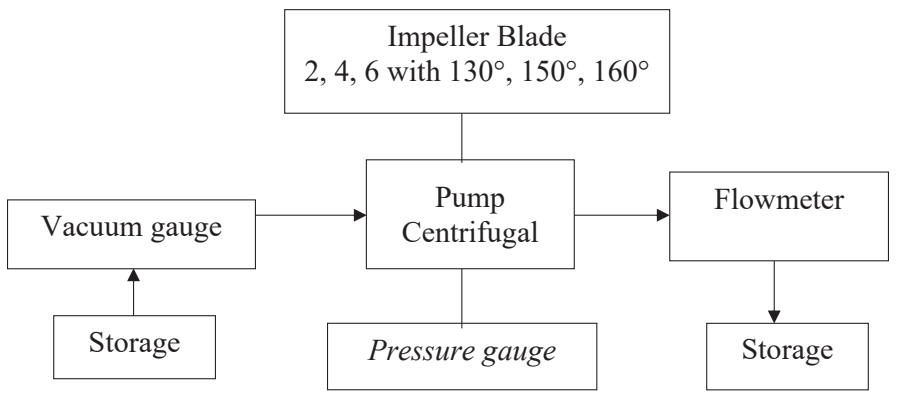

Fig. 2. The experimental setup

The research procedure includes:

1. Preparing the equipment according to the experimental setup.

2. Prepare the pump impeller with the number of blades and the angle to be tested.

3. Install the impeller on the volute housing and pump impeller housing.

4. Install the measuring instrument.

5. Data collection.

\section{3. Simulation}

Flow simulation using the solidworks program. This program can analyze the integrated and can simulate the flow of liquids that are adapted to actual conditions.

\section{3. 1. Boundary Conditions}

1. Initial Data Collection.

At this stage, data collection on information related to pumps is carried out with the number of blades 2, 4, and 6 and the angle of inclination of the blades $130^{\circ}, 150^{\circ}$, and $160^{\circ}$.

2. Parameter Setup Process.

In the simulation, the process to get results on the number and angle of the blades, setup parameters ranging from messing, boundary conditions, and goals. Referring to the internal type analysis, fluid type water, turbulent flow model, condition inlet (static pressure), outlet (total pressure) and adiabatic pump wall. 
3. Data Retrieval.

At the data collection stage, the simulation runs the process to get the results of the discharge and the total pressure generated on the number and angle of the blade angle.

\section{Result and Discussion}

\section{1. Result}

The results of the research are pump performance data including discharge, pump pressure as shown in Fig. 3, 4. The visual results of the pump flow simulation are as shown in Fig. $\mathbf{5 .}$

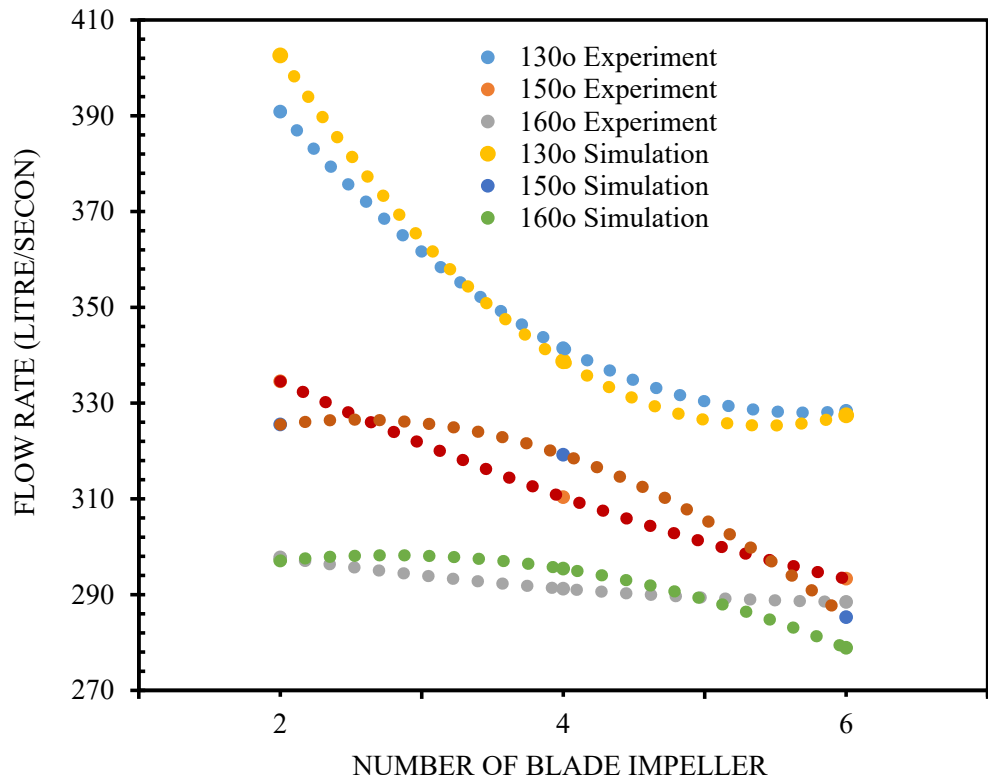

Fig. 3. Flow rate to the number of blades with variations in angles of $130^{\circ}, 150^{\circ}$ and $160^{\circ}$ in experiments and simulations

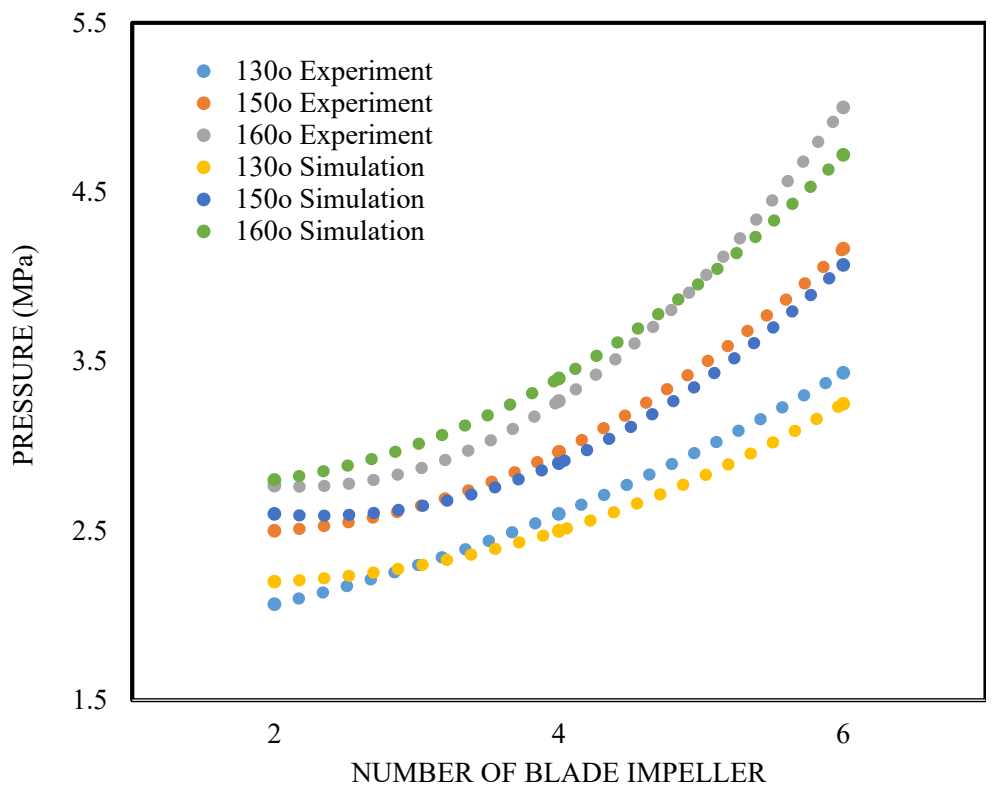

Fig. 4. Pump pressure on the number of blades with variations in angles of $130^{\circ}, 150^{\circ}$ and $160^{\circ}$ in experiments and simulations

Fig. 3 shows that there are three areas related to flow rate and discharge pressure: Area 1 is the pressure drop due to eddy currents in the opposite direction of rotation. Area 2 is a change 
in pressure because of the rotation of the blades, thus affecting the pump pressure. Area 3 is an occurrence of whirlpools caused by the flow of water hitting the impeller walls, causing the fluid flow to be restrained.

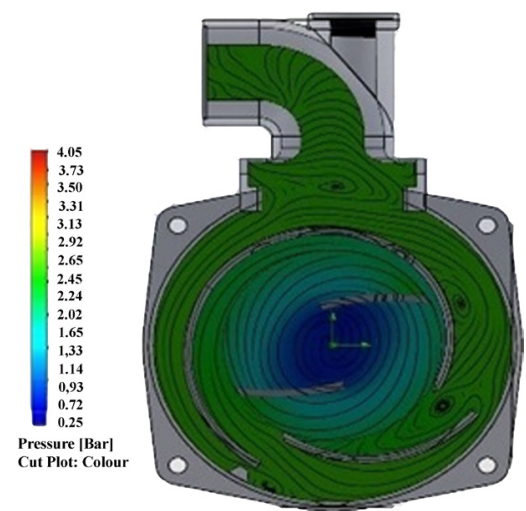

$a$
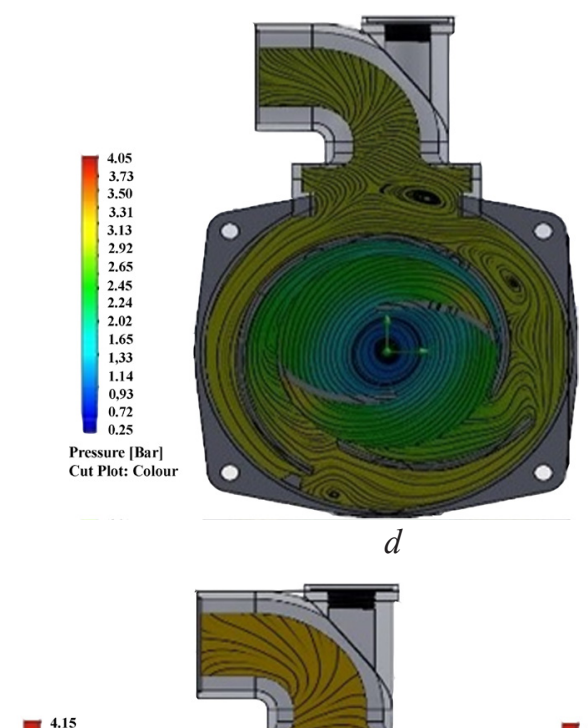

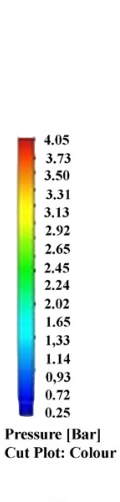

or]

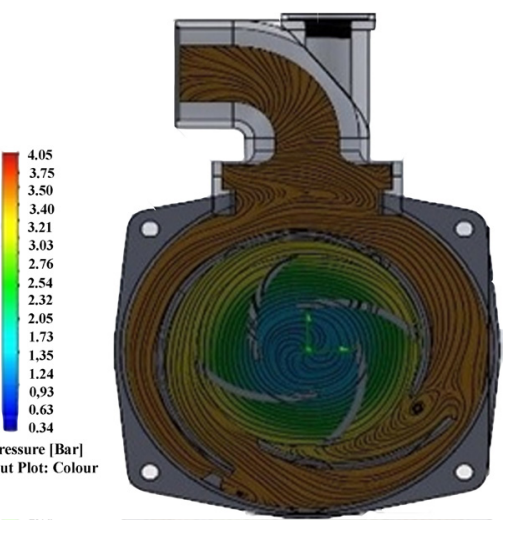

$e$
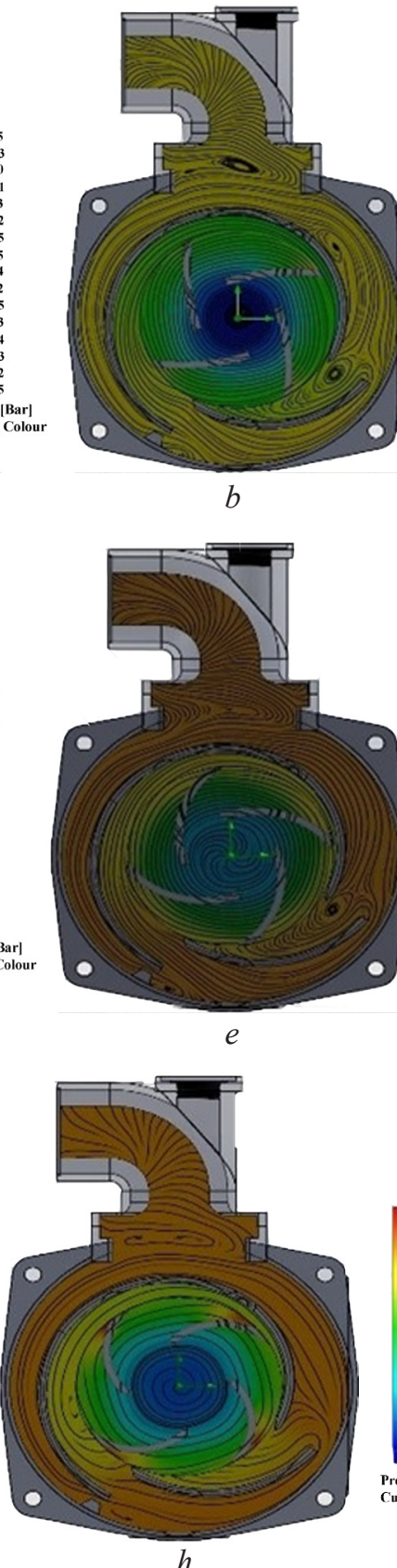

$b$

$h$

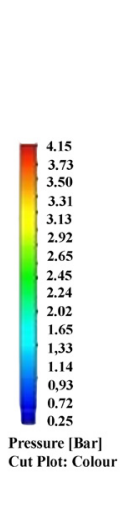

$g$

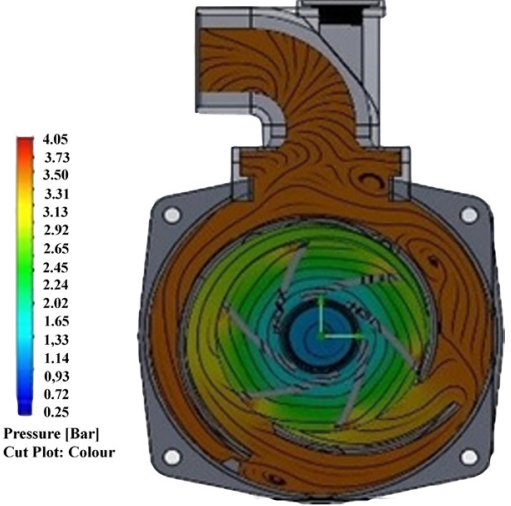

c
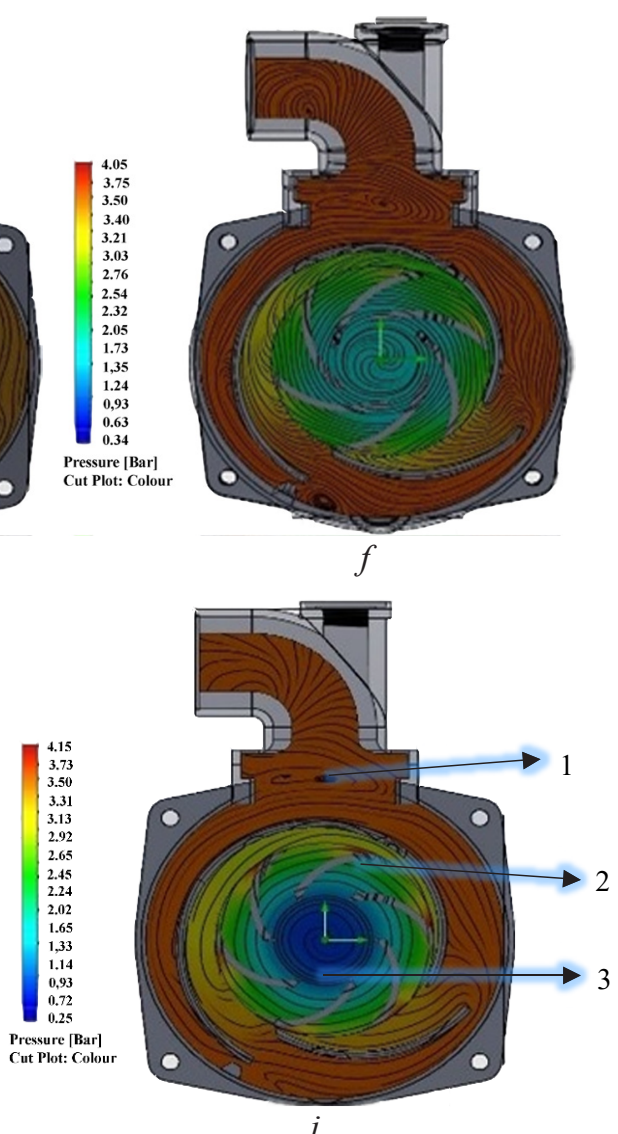

Fig. 5. Simulation results of variations in the number of blades and blade angles: $a-2$ blades, $130^{\circ} ; b-2$ blades $150^{\circ} ; c-2$ blades $160^{\circ} ; d-4$ blades $130^{\circ} ; e-4$ blades $150^{\circ}$; $f-4$ blades $160^{\circ} ; g-6$ blades $130^{\circ} ; h-6$ blades $150^{\circ} ; i-6$ blades $160^{\circ}$

\section{2. Discussion}

Based on the results of experiments and simulations got the number of blades 2, 4, and 6 with a tilt angle of $130^{\circ}, 150^{\circ}$, and $160^{\circ}$. In the volute outlet area, there is a pressure drop. This is because the whirlpool is in the opposite direction of the water flow.

In an impeller with several two blades and an angle of $130^{\circ}$, four vortex flows are in opposite directions of flow. This current is present at the volute outlet, volute wall and pump outlet line. 
That results in a pressure drop. The distance between the eddies also affects the pressure drop. The closer the distance between the vortexes, the greater the pressure drop, causing differences in fluid flow velocity. While the increase in the number of blades 4 and 6 , the pressure drop is getting smaller. An increase in the number of blades causes an increase in thrust pressure and an increase in fluid flow velocity.

In an impeller with two blades and an angle of $150^{\circ}$, there are three opposite vortices at the bottom of the volute housing line and the pump outlet line. However, the sum of the four blades caused a vortex. Its location, the housing volute outlet is next to the nearest vortex, while in the sixblade impeller, the vortex flow is at the bottom of the volute outlet. This is also almost the same as the angle of $130^{\circ}$. It's just that the location and pressure drop are different. As for the impeller with two blades and an angle of $160^{\circ}$, the pressure drops at the outlet side.

For the number of blades, four and six did not experience a decrease in pressure.

At the impeller inlet, there is a change in flow pressure. The change in colour level shows that. Where the more blades, the greater the pressure change. For two blades whose angles are $130^{\circ}, 150^{\circ}$, and $160^{\circ}$, there is a different pressure rise. An angle of $130^{\circ}$ the pressure increases $0.45-2.45$ bar, for an angle of $150^{\circ}$ it increases $-0.14-2.96$ bar and an angle of $160^{\circ}$ increases by 0.29-3.07 bar. For four blades with angles of $130^{\circ}, 150^{\circ}$ and $160^{\circ}$, there is a different pressure rise. For an angle of $130^{\circ}$, the pressure increases $0.48-3.12$ bar, for an angle of $150^{\circ}$ it increases by $0.39-3.39$ bar and an angle of $160^{\circ}$ increases by $0.36-3.48$ bar.

Even though the six-blade angles are $130^{\circ}, 150^{\circ}$, and $160^{\circ}$, there are differences where at the $130^{\circ}$ angle the pressure increases from 0.6 bar to $3.72 \mathrm{bar}$, for the $150^{\circ}$ angle it increases from $1.36-4.34$ bar, and at an angle of $160^{\circ}$, increase by $0.36-4.74$ bar.

In the area between the tip of the blade and the flow guide plate, there is a whirlpool caused by the flow of water hitting the impeller wall, causing a fluid flow to be obstructed. The large blade rotation produces a large resistance force so that the inflow is low. An increase in the number of blades will result in a decrease in the flow rate. The highest flow rate is found in the number of two blades with a blade angle of $130^{\circ}$. For comparison, the lowest flow rate is found in the six blades with an angle of $160^{\circ}$. There is a difference where the greater the number of blades and the greater the angle of the blade, the higher the pressure. The highest pressure is obtained in the amount of six blades with an angle of $160^{\circ}$, while the lowest pressure is obtained in the amount of two blades with an angle of $130^{\circ}$.

The research has not shown how much influence the number and angle of the blades on the pump impeller on the presence of cavitation, only discusses related to pump performance. In this study, only the impeller with the backward impeller type was used. So it is necessary to research other types.

It is necessary to develop pump studies related to the elimination of vortex flow that occurs at the outlet volute. This is very important because vortex flow increases the pressure drop. The presence of pressure drop in the outlet volute area causes the pump to cavitate. Cavitation is highly undesirable in a pumping system. Because of cavitation, the area of the fluid foam eruption experiences repeated shock pressures. So that shock pressure easily eroded the material in the area. In addition, losing pressure drop causes the flow to be smooth and without obstacles. So that the flow rate and the thrust of the fluid are getting bigger. This makes the pump performance better.

\section{Conclusions}

1. Pump performance related to discharge pressure, for an impeller with 2-blades and an angle of $130^{\circ}$, the pressure increases $0.45-2.45 \mathrm{bar}$, for $150^{\circ}$ increases $0.14-2.96 \mathrm{bar}$, and $160^{\circ}$ increases $0.29-3.07$ bars. For a 4-blade impeller and an angle of $130^{\circ}$, the pressure increases by $0.48-3.12$ bar, for $150^{\circ}$ it increases by $0.39-3.39$ bar, and for $160^{\circ}$ it increases by $0.36-3.48$ bar. While the impeller for 6-blades with an angle of $130^{\circ}$ the pressure increases from 0.6 bar to $3.72 \mathrm{bar}$, for $150^{\circ}$ increases from 1.36 to $4.34 \mathrm{bar}$, and $160^{\circ}$ increases by $0.36-4.74$ bar.

2. While it related pump performance to flow rate, increasing the number of blades causes a decrease in flow rate. The highest flow rate is in a 2-blade impeller with a blade angle of $130^{\circ}$ is $404.91 \mathrm{l} / \mathrm{s}$. The lowest flow rate is on a 6-blade impeller with an angle of $160^{\circ}$ is $279.66 \mathrm{l} / \mathrm{s}$. 


\section{Acknowledgments}

We are very grateful to the Department of Mechanical Engineering, State Polytechnic of Malang (Indonesia), to provide equipment support and be more mature in conducting an analysis.

\section{References}

[1] Aw-Hassan, A., Rida, F., Telleria, R., Bruggeman, A. (2014). The impact of food and agricultural policies on groundwater use in Syria. Journal of Hydrology, 513, 204-215. doi: https://doi.org/10.1016/j.jhydrol.2014.03.043

[2] Hanafizadeh, P., Ghorbani, B. (2012). Review study on airlift pumping systems. Multiphase Science and Technology, 24 (4), 323-362. doi: https://doi.org/10.1615/multscientechn.v24.i4.30

[3] Improving Pumping System Performance (2006). Department of Energy, 117. Available at: https://www.energy.gov/sites/ default/files/2014/05/f16/pump.pdf

[4] Singh, V. R., Zinzuwadia, M. J., Sheth, S., Desai, R. J. (2017). "Parametric Study and Design Optimization of Centrifugal Pump Impeller. Kalpa Publications in Engineering, 1, 507-515. doi: https://oi.org/10.29007/lbz2

[5] Asomani, S. N., Yuan, J., Wang, L., Appiah, D., Zhang, F. (2020). Geometrical effects on performance and inner flow characteristics of a pump-as-turbine: A review. Advances in Mechanical Engineering, 12 (4), 168781402091214. doi: https://oi.org/ $10.1177 / 1687814020912149$

[6] Sanda, B., Daniela, C. V. (2016). The influence of the inlet angle over the radial impeller geometry design approach with ansys. Journal of Engineering Studies and Research, 18 (4). doi: https://doi.org/10.29081/jesr.v18i4.146

[7] Subroto, Effendy, M. (2019). Optimization of centrifugal pump performance with various blade number. Exploring Resources, Process and Design for Sustainable Urban Development: Proceedings of the 5th International Conference on Engineering, Technology, and Industrial Application (ICETIA) 2018. doi: https://doi.org/10.1063/1.5112400

[8] Kim, J. H., Oh, K. T., Pyun, K. B., Kim, C. K., Choi, Y. S., Yoon, J. Y. (2012). Design optimization of a centrifugal pump impeller and volute using computational fluid dynamics. IOP Conference Series: Earth and Environmental Science, 15 (3), 032025. doi: https://doi.org/10.1088/1755-1315/15/3/032025

[9] Frosina, E., Buono, D., Senatore, A. (2017). A Performance Prediction Method for Pumps as Turbines (PAT) Using a Computational Fluid Dynamics (CFD) Modeling Approach. Energies, 10 (1), 103. doi: https://doi.org/10.3390/en10010103

[10] Li, W., Jiang, X., Pang, Q., Zhou, L., Wang, W. (2016). Numerical simulation and performance analysis of a four-stage centrifugal pump. Advances in Mechanical Engineering, 8 (10), 168781401667375. doi: https://doi.org/10.1177/1687814016673756

[11] Si, Q., Bois, G., Liao, M., Zhang, H., Cui, Q., Yuan, S. (2019). A Comparative Study on Centrifugal Pump Designs and Two-Phase Flow Characteristic under Inlet Gas Entrainment Conditions. Energies, 13 (1), 65. doi: https://doi.org/10.3390/ en13010065

How to cite: Susilo, S. H., Setiawan, A. (2021). Analysis of the number and angle of the impeller blade to the performance of centrifugal pump. EUREKA: Physics and Engineering, 5, 62-68. doi: https://doi.org/10.21303/2461-4262.2021.002001 